\title{
Candida albicans isolates from HIV-infected and AIDS patients exhibit enhanced adherence to epithelial cells
}

\author{
S. P. SWEET, SHARON COOKSON and S. J. CHALLACOMBE
}

Centre for the Study of Oral Manifestations of HIV Infection, Department of Oral Medicine and Pathology, UMDS Guy's Hospital, London SE1 9RT

\begin{abstract}
Summary. The increased prevalence of oral candidosis associated with HIV infection must be intrinsically related to immunological changes in the host, but might also involve alterations to the infecting strains of yeast. This study aimed to determine if strains of Candida albicans isolated from asymptomatic HIV-infected individuals or AIDS patients possessed altered adherence properties in an in-vitro buccal epithelial cell (BEC) adherence assay. C. albicans isolates from 49 patients with HIV infection or AIDS adhered to BEC in significantly higher numbers than isolates from 49 control subjects $(p<0.001)$. No significant differences in adherence were detected between strains isolated from HIV-infected or AIDS subjects, or between strains isolated from $C$. albicans carriers (low salivary $C$. albicans counts) or subjects with oral candidosis. The presence of whole saliva significantly inhibited the binding of candida to BEC $(\mathrm{p}<0.001)$, but the significant difference in adherence between the HIV/AIDS and control isolates was maintained. The effect of saliva was independent of salivary candida antibodies and was abolished by treatment with protease or neuraminidase, suggesting the involvement of salivary mucins. The results of this study suggest that HIV infection is associated with the selection of strains of C. albicans with an increased ability to adhere to oral mucosa.
\end{abstract}

\section{Introduction}

Candida species are carried as part of the commensal oral flora of c. $40 \%$ of healthy individuals, normally without disease. ${ }^{1}$ However, various factors can predispose to candidosis, including diabetes, pregnancy, antibiotic therapy and, in particular, HIV infection. Candidosis is the most common oral manifestation of HIV infection and is recognised as an important indicator of HIV disease and its progression. The first documented patient with AIDS displayed symptoms of oral candidosis ${ }^{2}$ and it has been demonstrated that the frequency of isolation of Candida spp. and clinical signs of oral candidosis increase with advancing HIV infection, ${ }^{3.4}$ making it an important predictive sign for the subsequent development of AIDS. ${ }^{5}$

Adherence to an oral surface is essential to initiate the process of colonisation and infection. ${ }^{6}$ Therefore, the binding of $C$. albicans to the oral mucosa must be a pre-requisite for infection and may be regarded as the first step in the process culminating in oral candidosis. Numerous studies have addressed the question of the

Received 30 Jan. 1995: revised version received 4 May 1995 ; accepted 10 May 1995 mechanisms involved in the complex process of yeast adhesion to epithelial cells and other surfaces. A number of investigators have concentrated on identifying the terminal sugars of the host cell surface glycoproteins that interact with the fungal cell wall. ${ }^{\text {? }}$ Sugars such as L-fucose, $\mathrm{N}$-acetylglucosamine, mannosamine, glucosamine and galactosamine were found to inhibit adhesion. ${ }^{7,8}$ Also, a number of putative adhesins of $C$. albicans have been studied including cell-wall chitin, ${ }^{9,10}$ lipids, ${ }^{11}$ complement receptors, ${ }^{12,13}$ mannan, ${ }^{14,15}$ proteins ${ }^{16,17}$ and in particular mannoproteins. ${ }^{18,19}$ Evidence suggests that mannoproteins of $C$. albicans are the principle adhesins responsible for adhesion to host cells, and these have been partially characterised. ${ }^{18,20,21}$ Other biophysical factors have also been seen to greatly influence yeast binding to epithelial cells, including cell-surface hydrophobicity, ${ }^{22,}{ }^{23} \mathrm{pH}$, carbon dioxide and iron concentrations. ${ }^{24-26}$ These studies allude to the adherence of $C$. albicans as a specific, multifactorial process involving several types of candidal cell-surface adhesins and various binding sites on host cells.

Recently it has been suggested from DNA fingerprinting, ${ }^{27-29}$ karyotyping ${ }^{30}$ and phenotyping ${ }^{31}$ studies that HIV infection might be associated with the 
selection of C. albicans strains resulting in replacement of the original commensal strains. It is feasible that this process is related to the selection of strains with altered virulence determinants leading to colonisation with Candida populations that are more able to cause disease in immunologically compromised hosts. If this process of selection is indeed related to pathogenicity, it may be possible to measure alterations in virulence determinants, such as the ability to adhere to oral mucosal tissues. Therefore, the aims of this study were to determine if strains of Candida isolated from patients with HIV infection and AIDS possess altered adherence properties in an in-vitro buccal epithelial cell (BEC) adherence assay.

\section{Materials and methods}

\section{Source of C. albicans isolates}

Strains of $C$. albicans were isolated from $49 \mathrm{HIV}$ antibody-positive patients and 49 control subjects. The HIV-infected subjects consisted of 41 patients with no AIDS-defining illnesses with a mean age of 35 years (range 20-58), and eight AIDS patients with a mean age of 42 years (range 24-61). The control subjects consisted of 49 patients with a mean age of 43 years (range 20-78) attending an oral medicine clinic and presenting with various oral pathologies such as xerostomia, recurrent oral ulceration or lichen planus, and not known to be at risk of HIV infection. The control patients were selected as a group with an increased susceptibility to oral candidosis but without evidence of immunosuppression. The majority of the asymptomatic HIV-infected patients and control subjects and two of the AIDS patients had no history of antibiotic or antimycotic therapy in the previous year, and none was receiving antibiotics or antimycotics at the time of sampling. Saliva cultures indicated that 22 of the $41 \mathrm{HIV}$ patients, five of the eight AIDS patients, and 30 of the 49 control subjects had high yeast counts indicative of oral candidosis ( $>1000 \mathrm{cfu} / \mathrm{ml}$ of saliva).

\section{Isolation of C. albicans}

Yeasts were isolated from $100 \mu$ l of whole saliva on Sabouraud's dextrose agar (SAB) as described previously. ${ }^{32}$ Yeast $\mathrm{cfu}$ were counted after incubation for 2 days at $37^{\circ} \mathrm{C}$. Representative colonies were subcultured and $C$. albicans isolates were selected after identification with the API 20 AUX system (biomerieux, Marcy l'Etoile, France), chlamydospore production on corn-meal agar and germ-tube production in serum. Yeasts were stored as SAB stab cultures at $4^{\circ} \mathrm{C}$ and in glycerol $40 \%$ at $-20^{\circ} \mathrm{C}$.

\section{Candida suspensions}

Suspensions were prepared from $C$. albicans grown on SAB agar for $48 \mathrm{~h}$ at $37^{\circ} \mathrm{C}$. A single colony was suspended in $10 \mathrm{ml}$ of phosphate-buffered saline (PBS), pH 7.2 and washed three times by centrifugation at $2500 \mathrm{~g}$ for $10 \mathrm{~min}$. The yeast cell concentration was determined with a haemocytometer and adjusted to $10^{7}$ cells $/ \mathrm{ml}$.

\section{Buccal epithelial cells (BEC)}

BEC were collected from healthy laboratory personnel with no signs or symptoms of oral candidosis or other oral pathology. None was taking antibiotics at any time during the study. Some experiments were performed with BEC from six males with a mean age of 31 years (range 23-37) and six females with a mean age of 27 years (range 22-30). However, the majority of experiments were done with BEC from a 22-yearold female.

BEC were collected, at the same time each day, by gently rubbing the buccal mucosa with a sterile cotton wool swab. Cells were dislodged from the swab by agitating in $10 \mathrm{ml}$ of PBS, pH 7.2. The cells were passed through $70-\mu \mathrm{m}$ pore-size filters (Becton Dickinson, Lincoln Park, NJ, USA) to remove sheets and clumps of cells, then washed three times in PBS by centrifugation at $2500 \mathrm{~g}$ for $10 \mathrm{~min}$ before resuspending to a concentration of $10^{5} \mathrm{cells} / \mathrm{ml}$, measured with a haemocytometer.

\section{Adherence assay}

The adherence assay used has been described previously ${ }^{26}$ Briefly, $100-\mu$ samples of BEC and yeast cell suspensions (100 yeasts: 1 BEC) were mixed in sterile plastic 7-ml screw-capped bottles and incubated with shaking at $37^{\circ} \mathrm{C}$. After $45 \mathrm{~min}, 5 \mathrm{ml}$ of PBS were added to each bottle to minimise further attachment. BEC with attached yeasts were collected on $25-\mathrm{mm}$ diameter, $12-\mu \mathrm{m}$ pore-size polycarbonate filters (Nuclepore, High Wycombe) and washed twice with $5 \mathrm{ml}$ of PBS to remove unattached yeast cells. The filters were then air dried and Gram stained. The number of yeasts adhering to $100 \mathrm{BEC}$ was determined by light microscopy at a magnification of $\times 400$. $C$. albicans NCPF 3153 was included in each batch of assays as an internal control. Assays were done in duplicate and data were analysed by an unpaired $t$ test.

\section{Addition of saliva}

BEC and C. albicans were suspended in a 1 in 10 dilution of whole saliva obtained from the BEC donor. Saliva was clarified by centrifuging at $20000 g$ for $10 \mathrm{~min}$. In addition, some saliva samples were depleted of $C$. albicans antibodies by adsorbing saliva with formalin-fixed C. albicans NCPF 3153 cells according to the method of Coogan et al ${ }^{32}$ Adsorbed saliva contained no measurable levels of Candida-specific antibodies as determined by ELISA.$^{32}$ As a control, saliva samples were also adsorbed with formalin-fixed Escherichia coli. Some saliva samples were also incubated at $37^{\circ} \mathrm{C}$ with protease (pronase E; Sigma) to a 
final concentration of $0.05 \mathrm{mg} / \mathrm{ml}$ for $1 \mathrm{~h}$, then proteolysis was stopped by the addition of a one-tenth volume of $0.05 \mathrm{mM}$ phenylmethylsulphonyl fluoride (PMSF). Saliva was also incubated at $37^{\circ} \mathrm{C}$ for $1 \mathrm{~h}$ with neuraminidase (Sigma) 20 units $/ \mathrm{ml}$, followed by heating at $56^{\circ} \mathrm{C}$ for $1 \mathrm{~h}$ to inactivate the enzyme.

\section{Results}

Adherence of C. albicans from $H I V$-infected subjects, AIDS patients and controls

The mean numbers of adherent $C$. albicans were significantly higher with the isolates from HIVinfected and AIDS patients compared with the control isolates ( $p<0.001$; fig. 1). The HIV and AIDS isolates adhered in similar numbers and demonstrated a mean $40 \%$ increase in adherence compared with the control isolates. The addition of whole saliva significantly inhibited the binding of the HIV, AIDS and control $C$. albicans isolates $(\mathrm{p}<0.001)$ by a mean of 33,44 and $62 \%$, respectively. The significant difference in adherence between the HIV or AIDS isolates and the control isolates was still evident regardless of the presence of saliva in the assay system ( $p<0.001$; fig. 1). A previous history of antibiotic or antimycotic use within the previous year by the HIV and AIDS patients had no effect on adherence.

\section{Candidal carriage versus candidosis}

Analysis of the adherence data according to whether isolates were obtained from patients with oral candidosis $\left(>10^{3} \mathrm{cfu} / \mathrm{ml}\right.$ saliva $)$ or from patients with

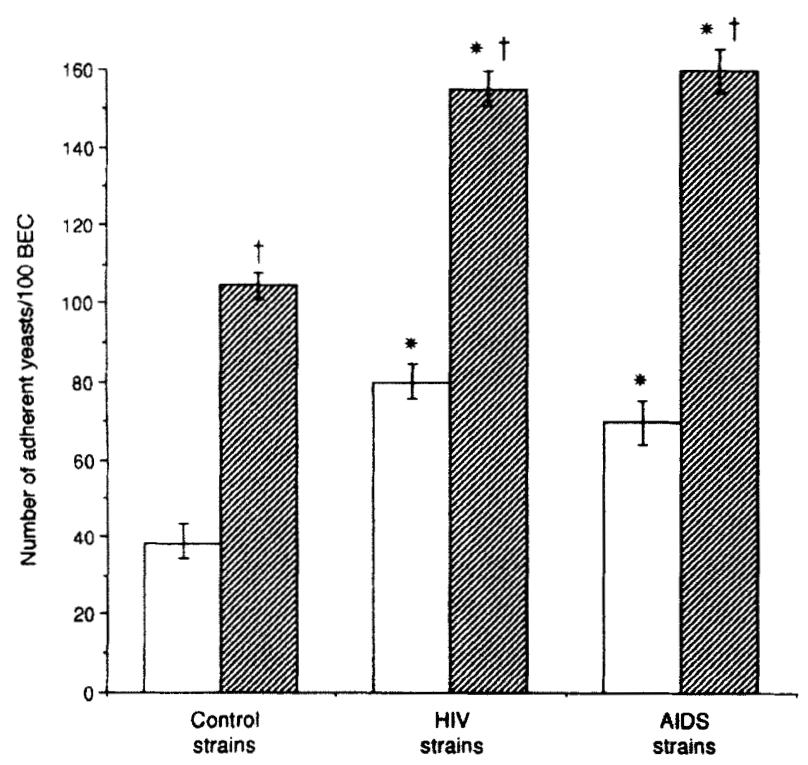

Fig. 1. Adherence of C. albicans strains isolated from controls, HIVinfected or AIDS patients to BEC suspended in PBS with no saliva (D); or in PBS with a 1 in 10 dilution of saliva ( $\square$ ). Bars represent the SEM. * Significant difference in mean adherence levels of the HIV and AIDS isolates compared with the control strains $(p<$ $0.001)$. + Significant difference in mean adherence levels of the HIV, AIDS and control isolates suspended in PBS compared with a 1 in 10 dilution of saliva $(\mathrm{p}<0.001)$.

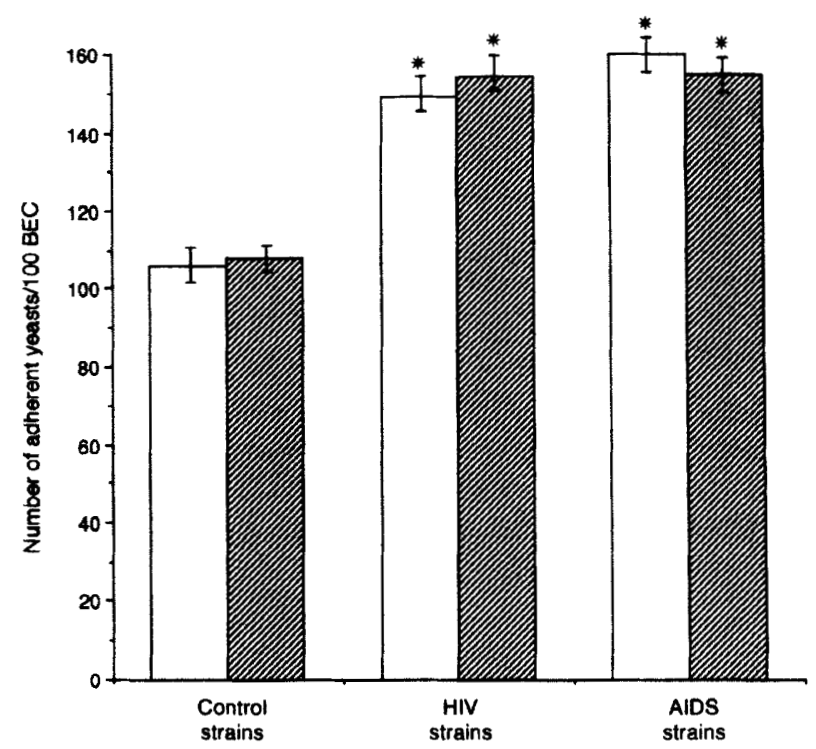

Fig. 2. Adherence of $C$. albicans strains isolated from controls, HIVinfected or AIDS patients with low levels of candidal carriage $(\square)$ (carriers; $<1000 \mathrm{cfu} / \mathrm{ml}$ of saliva) or with candidosis $(\square)(>1000$ yeast $\mathrm{cfu} / \mathrm{ml}$ of saliva), to BEC suspended in PBS (no saliva). Similar results were obtained with cells suspended in PBS with saliva ( 1 in 10 dilution). Bars represent the SEM. ${ }^{*}$ Significant difference in mean adherence levels of the HIV and AIDS isolates compared with the control strains $(\mathrm{p}<0.001)$.

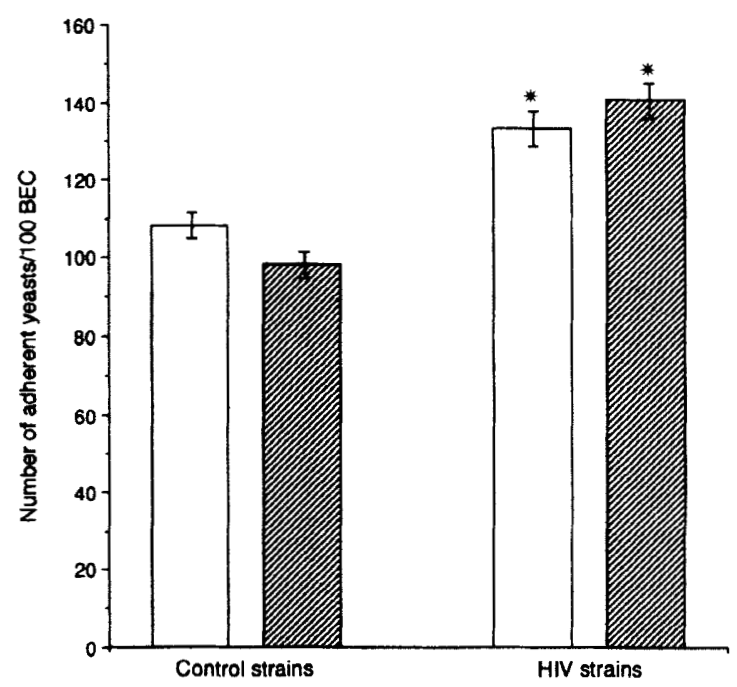

Fig. 3. Adherence of $C$. albicans strains isolated from control or HIV-infected patients to BEC from male $(\square)$ or female $(\square)$ donors, and suspended in PBS (no saliva). Bars represent the SEM. * Significant difference in mean adherence levels of the HIV isolates compared with the control strains $(\mathrm{p}<0.001)$.

low salivary $C$. albicans counts $\left(<10^{3} \mathrm{cfu} / \mathrm{ml}\right)$ showed no significant differences in mean levels of adherence between the two groups (fig. 2). This was evident with the HIV, AIDS and control isolates, and in the presence or absence of saliva.

\section{BEC from male and female donors}

Adherence assays were performed with six HIV and six control C. albicans isolates and with BEC obtained from six female and six male subjects. There were no significant differences in mean adherence levels between the male and female BEC, with either the HIV or control isolates (fig. 3). The increased adherence of 


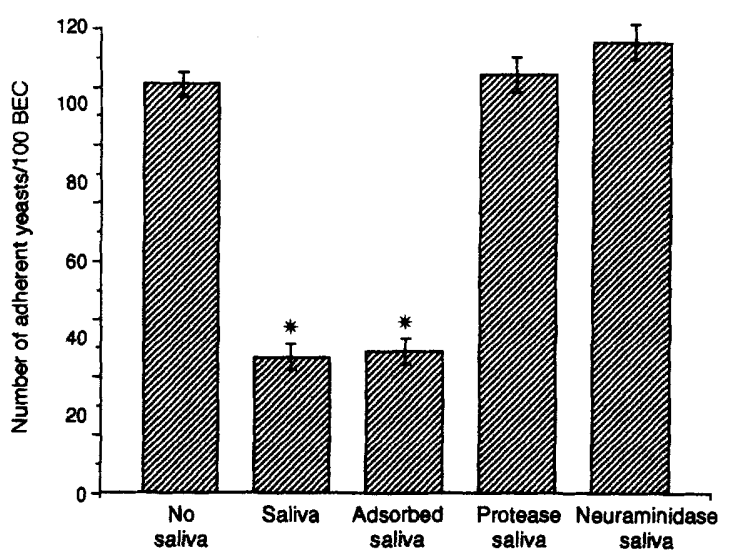

Fig. 4. Adherence of a control isolate of $C$. albicans to BEC suspended in PBS or in PBS with 1 in 10 dilutions of saliva, adsorbed saliva depleted of $C$. albicans antibodies, protease-treated saliva or neuraminidase-treated saliva. Bars represent the SEM. * Significant difference in mean adherence levels with saliva or adsorbed saliva compared with no saliva or protease- or neuraminidase-treated saliva $(\mathrm{p}<0.001)$.

the HIV isolates, noted with the previous experiments with a single female donor, were maintained with BEC from all of the donors.

\section{Inhibition of adherence by saliva}

The mechanism of salivary inhibition of adherence was investigated with a single control strain of $C$. albicans. Addition of saliva to the assay system produced a significant decrease in adherence of $64 \%$ ( $p<0.001$; fig. 4). Substitution of antibody-depleted saliva previously adsorbed with formalin-fixed $C$. albicans (or E. coli), showed similar levels of inhibition of adherence (fig. 4). In contrast, treatment of saliva with either protease or neuraminidase eliminated the inhibitory effects of saliva (fig. 4).

\section{Discussion}

The proposed requirement for adhesion as the first step in the process of colonisation and infection of a host has led to the development of a number of adherence assay systems. A widely used model to study the adherence of Candida spp. and other oral micro-organisms utilises an in-vitro buccal cell adhesion assay. However, this method has limitations. For example, the receptiveness of both buccal and vaginal epithelial cells for $C$. albicans can vary significantly between donors and from day-to-day with the same donor. ${ }^{33-35}$ It has been postulated that the hormonal status of the donor may influence adherence, ${ }^{34}$ and that fluctuations in hormone levels in menstruating females may affect the adherence of $C$. albicans to vaginal epithelial cells. ${ }^{36}$ More recently Theaker et $\mathrm{l}^{37}$ reported that adherence of C. albicans to buccal cells also varied with changes in the menstrual cycle, although this conclusion was based on BEC from only one female donor. A retrospective analysis of adherence data from this study showed no influence on candidal adherence due to the hormonal cycles of the female donor used for most of the present study. Furthermore, no significant differences in adherence were found with BEC obtained from male or female donors (fig. 3).

The results of this study suggest that HIV infection and AIDS is associated with the selection of strains of C. albicans with an enhanced ability to adhere to BEC (fig. 1). The HIV and AIDS $C$. albicans isolates adhered in similar numbers, and nearly all of these strains adhered better than all of the control isolates. The presence in the HIV group of healthy, asymptomatic patients suggests that the selection of $C$. albicans strains with altered adherence properties occurs early in the course of HIV infection, before symptoms of immune deficiency are evident and prior to the sequelae of opportunist mucosal infections and consequent treatment regimens. Therefore, the apparent selection of C. albicans in HIV infection appears to be independent of antifungal or antibiotic use or other treatments. The selection of more adherent $C$. albicans may contribute to the predisposition of HIV-infected individuals to oral candidosis; however, increased adherence did not correlate with the presence of oral candidosis (fig. 2), suggesting that, as might be expected, other factors must also act to predispose the host to infection. The influence of HIV infection on other virulence determinants of $C$. albicans remains to be determined, as does the role of HIV-induced immunosupression versus immunosuppression due to other causes.

The enhancement of adhesion in HIV infection and AIDS was also evident in the presence of saliva, despite up to $60 \%$ inhibition of adherence, suggesting that this process may be functional in vivo. Saliva was approximately twice as effective at inhibiting adherence of the control C. albicans compared with the HIV and AIDS isolates, indicating that the apparent selection of C. albicans in HIV infection may relate to avoidance of the adherence-moderating effect of saliva. Whilst micro-organisms must adhere to an oral surface to avoid the flushing action of saliva, host responses are aimed at limiting adherence and colonisation. Saliva contains various components with antifungal activity, including lysozyme, lactoferrin, lactoperoxidase, calprotectin and histidine-rich polypeptides that may help to control oral candidal populations. ${ }^{38}$ Alterations to salivary composition or to mucosal tissues as a result of HIV infection may provide the selective pressures necessary to induce alterations in the populations of colonising microorganisms.

Salivary immunoglobulin A (IgA) has been implicated in the inhibition of candidal adherence to host surfaces and may function primarily by binding to the surface of specific micro-organisms and interfering with cell-to-cell interactions. ${ }^{39}$ The role of immunoglobulins or other specific factors in the inhibition of adherence was investigated with saliva samples adsorbed with suspensions of formalin-fixed $C$. 
albicans (fig. 4). Adsorbed saliva samples contained no measurable IgA by ELISA. However, both adsorbed and unadsorbed saliva showed a significant inhibition of $C$. albicans binding, suggesting that the components in saliva able to inhibit $C$. albicans binding in this assay are probably not antibody related. These results contradict previous studies showing that a decrease in anti-candida titres due to immunoprecipitation of $\operatorname{IgA}$ from saliva correlated with increased adherence. ${ }^{39}$ However, the protective function of salivary $\operatorname{IgA}$ in HIV infection has been questioned. HIV-infected patients with oral candidosis have been shown to produce increased levels of salivary candida IgA antibodies, indicating that secretory antibodies are produced in response to infection, but episodes of oral candidosis frequently recur. ${ }^{32}$

Non-specific salivary components may also

\section{References}

1. Arendorf TM, Walker DM. The prevalence and intra-oral distribution of Candida albicans in man. Arch Oral Biol $1980 ; 25: 1-10$

2. Gottlieb MS, Schanker HM, Fan PT, Saxon A, Weismann JO, Pozalski 1. Pneumocystis pneumonia-Los Angeles. MMWR 1981; 30:250-251

3. Torrssander J, Morfeldt-Månsen L, Biberfeld G, Karlssen A, Putkonen P-O, Wasserman J. Oral Candida albicans in HIV infection. Scand J Infect Dis 1987; 19: 291-295.

4. Korting HC, Ollert $\mathbf{M}$, Georgii $\mathrm{A}$, Fröschl $\mathrm{M}$. In titro susceptibilities and biotypes of Candida albicans isolates from oral cavities of persons infected with Human Immunodeficiency Virus. $J$ Clin Microbiol 1988; 26 2626-2631

5. Klein RS, Harris CA, Small CB, Moll B, Lesser M, Friedland GH. Oral candidiasis in high-risk patients and the initial manifestation of the Acquired Immunodeficiency Syndrome. N Engl J Med 1984; 311 : 354-358.

6. Gibbons RJ, van Houte J. Bacterial adherence in oral microbial ecology. Annu Rev Microbiol 1975: 29: 19-44.

7. Critchley IA, Douglas LJ. Role of glycosides as epithelial cell receptors for Candida albicans. J Gen Microbiol 1987; 133 637643

8. Collins-Lech C. Kalbfleisch JH. Franson TR, Sohnle PG Inhibition by sugars of Candida albicans adherence to human buccal mucosal cells and corneocytes in vitro. Infect Immun 1984; 46:831-834.

9. Segal E, Lehrer N, Ofek I. Adherence of Candida albicans to human vaginal epithelial cells: inhibition by amino sugars. Exp Cell Biol 1982; 50: 13-17.

10. Lehrer N, Segal E, Lis H, Gov Y. Effect of Candida albicans cell wall components on the adhesion of the fungus to human and murine vaginal mucosa. Mycopathologia 1988: 102 : $115-121$

11. Ghannoum MA, Burns GR, Elteen KA, Radwan SS. Experimental evidence for the role of lipids in adherence of Candida spp. to human buccal epithelial cells. Infect Immun 1986: $54: 189-193$

12. Gilmore BJ, Retsinas EM, Lorenz JS, Hostetter MK. An iC3b receptor on Candida albicans: structure, function, and correlates for pathogenicity. J Infect Dis 1988; 157: 38-46.

13. Alaei S, Larcher C, Ebenbichler C. Prodinger WM, Janatova J, Dierich MP. Isolation and biochemical characterization of the $\mathrm{iC} 3 \mathrm{~b}$ receptor of Candida albicans. Infect Immun 1993; 61: 1395-1399.

14. Sandin RL. Studies on cell adhesion and concanavalin Ainduced agglutination of Candida albicans after mannan extraction. J Med Microbiol 1987: 24: 145-150.

15. Miyakawa Y, Kuribayashi T, Kagaya K, Suzuki M, Nakase T Fukazawa $Y$. Role of specific determinants in mannan of Candida albicans serotype $\mathrm{A}$ in adherence to human buccal epithelial cells. Infect Immun 1992; 60: 2493-2499.

16. Critchley IA. Douglas LJ. Isolation and partial characterization influence adhesion interactions. Salivary glycoproteins have been shown to inhibit the attachment of oral streptococci to buccal cells, ${ }^{40}$ but mucins may also promote the adherence of streptococci to solid surfaces $^{41}$ via neuraminidase-sensitive sialic acid residues. ${ }^{42}$ Comparatively few studies have investigated interactions between Candida spp. and salivary components, although the salivary constituents bound by $C$. albicans have been shown to consist predominantly of low mol.-wt mucins. ${ }^{43}$ The observation that treatment with neuraminidase or protease effectively abolished the ability of saliva to inhibit candidal adherence (fig. 4) concurs with the implication of mucinous glycoproteins as adherence modulating factors.

This study was supported by the Oral and Dental Research Trust and the Dunhill Medical Trust.

of an adhesin from Candida albicans. J Gen Microbiol 1987 133: 629-636.

17. Calderone RA, Scheld WM. Role of fibronectin in the pathogenesis of candidal infections. Rev Infect Dis 1987; 9 Suppl 4: $\mathrm{S} 400-\mathrm{S} 403$

18. Tosh DF, Douglas LJ. Characterization of a fucoside-binding adhesin of Candida albicans. Infect Immun 1992; 60: 4734-4739.

19. Calderone RA. Molecular interactions at the interface of Candida albicans and host cells. Arch Med Res 1993; 24: 275-279.

20. Kanbe T, Han Y, Redgrave B, Riesselman MH, Cutler JE Evidence that mannans of Candida albicans are responsible for adherence of yeast forms to spleen and lymph node tissue. Infect Immun 1993; 61: 2578-2584.

21. Li RK, Cutler JE. Chemical definition of an epitope/adhesin molecule on Candida albicans. J Biol Chem 1993; 268 : 18293-18299.

22. Hazen KC, Glee PM. Hydrophobic cell wall protein glycosylation by the pathogenic fungus Candida albicans. Can J Microbiol 1994; 40: 266-272.

23. Ener B, Douglas LJ. Correlation between cell-surface hydrophobicity of Candida albicans and adhesion to buccal epithelial cells. FEMS Microbiol Lett 1992; 78: 37-42.

24. Samaranayake LP, MacFarlane TW. Factors affecting the in vitro adherence of the fungal oral pathogen Candida albicans to epithelial cells of human origin. Arch Oral Biol 1982; 27 : 869-873.

25. Persi MA, Burnham JC, Duhring JL. Effects of carbon dioxide and $\mathrm{pH}$ on adhesion of Candida albicans to vaginal epithelial cells. Infect Immun 1985; 50: 82-90.

26. Sweet SP, Douglas LJ. Effect of iron deprivation on surface composition and virulence determinants of Candida albicans. J Gen Microbiol 1991; 137: 859-865.

27. Challacombe SJ, Muir J, Howell SA, Sweet SP. Genetic variability of Candida albicans in HIV infection. Microb Ecol Hlth Dis 1995; 8: 63-70.

28. Anthony RM, Midgley J, Sweet SP, Howell SA. Multiple strains of Candida albicans in the oral cavity of HIV positive and HIV negative patients. Microb Ecol Hlth Dis 1995; 8: 23-30.

29. Schmid J, Odds FC, Wiselka MJ, Nicholson KG, Soll DR. Genetic similarity and maintenance of Candida albicans strains from a group of AIDS patients, demonstrated by DNA fingerprinting. J Clin Microbiol 1992; 30: 935-941.

30. Pfaller MA, Rhine-Chalberg J, Redding SW et al. Variations in fluconazole susceptibility and electrophoretic karyotype among oral isolates of Candida albicans from patients with AIDS and oral candidiasis. J Clin Microbiol 1994; 32 59-64.

31. Gallagher PJ, Bennett DE, Henman MC et al. Reduced azole susceptibility of oral isolates of Candida albicans from HIV-positive patients and a derivative exhibiting colony morphology variation. J Gen Microbiol 1992; 138 1901-1911 
32. Coogan MM, Sweet SP, Challacombe SJ. Immunoglobulin A (IgA), IgA1, and IgA2 antibodies to Candida albicans in whole and parotid saliva in human immunodeficiency virus infection and AIDS. Infect Immun 1994; 62: 892-896.

33. Kearns MJ, Davies $P$, Smith $H$. Variability of the adherence of Candida albicans strains to human buccal epithelial cells: inconsistency of differences between strains related to virulence. Sabouraudia $1983 ; 21$ : 93-98.

34. King RD, Lee JC, Morris AL. Adherence of Candida albicans and other Candida species to mucosal epithelial cells. Infect Immun 1980; 27: 667-674.

35. Sobel JD, Myers PG, Kaye D, Levison ME. Adherence of Candida albicans to human vaginal and buccal epithelial cells. J Infect Dis 1981; 143: 76-82.

36. Botta GA. Possible role of hormones in the observed changes in adhesion of several micro-organisms to epithelial cells of different body sites. FEMS Microbiol Lett 1981; 11 : 69-72.

37. Theaker ED, Drucker DB, Gibbs ACC. The possible influence of the menstrual cycle on the adherence of Candida albicans to human buccal epithelial cells in vitro. Arch Oral Biol $1993 ; 38$ : 353-355.
38. Challacombe SJ. Immunology of oral candidosis. In: Samaranayake LP, MacFarlane TW (eds) Oral candidosis. London, Wright. 1990: 104-123.

39. Epstein JB, Kimura LH, Menard TW, Truelove EL, Pearsall NN. Effects of specific antibodies in the interaction between the fungus Candida albicans and human oral mucosa. Arch Oral Biol 1982; 27: 469-474.

40. Williams RC, Gibbons RJ. Inhibition of streptococcal attachment to receptors on human buccal epithelial cells by antigenically similar salivary glycoproteins. Infect Immun 1975; 11: 711-718.

41. Lightenberg AJM, Walgreen-Weterings E, Veerman ECI, de Soet JJ, de Graaf J, Nieuw Amerongen AV. Influence of saliva on aggregation and adherence of Streptococcus gordonii HG 222. Infect Immun 1992; 60: 3878-3884.

42. Murray PA, Prakobphol A, Lee T, Hoover CI, Fisher SJ. Adherence of oral streptococci to salivary glycoproteins. Infect Immun 1992; 60: 31-38.

43. Hoffman MP, Haidrais CG. Analysis of Candida albicans adhesion to salivary mucin. Infect Immun 1993; 61: 1940-1949. 